\title{
CORRIGENDA
}

\section{The Fourth Arginine Catabolic Pathway of Pseudomonas aeruginosa}

By ALFRED JANN, HIDEKI MATSUMOTO AND DIETER HAAS

Journal of General Microbiology (1988), 134, 1043-1053

p. 1044, Fig. 1.

The reaction catalysed by enzyme 10 in the arginine succinyltransferase pathway should be represented as follows:

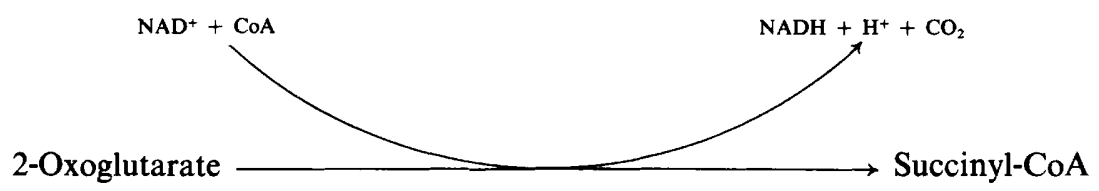

(10)

p. 1049, Fig. 4 .

The second sentence of the legend should read 'Transducing phage F116L and strains PAO332, PAO4155 and kauB::Tn5-751 derivatives of PAO303 and PAO483 were used'.

The Rate and Topography of Cell Wall Synthesis during the Division Cycle of Escherichia coli using $\boldsymbol{N}$-Acetylglucosamine as a Peptidoglycan Label

By STEPHEN COOPER AND MING LIN HSIEH

Journal of General Microbiology (1988), 134, 1717-1721.

The equation on p. 1718 was incorrect; the correct version is as follows.

$$
\frac{\mathrm{d} A / \mathrm{d} t}{\mathrm{~d} M / \mathrm{d} t}=1+\frac{6 h_{\alpha}^{2}}{2^{\alpha} \ln 2\left(1-T_{\mathrm{c}}\right)\left(4 r^{2}+3 r L_{0_{\mathrm{cy}}}\right)}
$$

